\title{
Transpancreatic Sphincterotomy Is Effective and Safe in Expert Hands on the Short Term
}

\author{
Dániel Pécsi ${ }^{1}$ (D) Nelli Farkas ${ }^{1,2} \cdot$ Péter Hegyi $^{1,3,4} \cdot$ Péter Varjú $^{1} \cdot$ Zsolt Szakács $^{1}$ - Anna Fábián ${ }^{4}$. Gábor Varga ${ }^{5}$. \\ Zoltán Rakonczay Jr. ${ }^{6} \cdot$ Emese Réka Bálint $^{6} \cdot$ Bálint Erőss $^{1} \cdot$ József Czimmer $^{7} \cdot$ Zoltán Szepes $^{4} \cdot$ Áron Vincze $^{7}$
}

Received: 11 November 2018 / Accepted: 23 April 2019 / Published online: 4 May 2019

(C) The Author(s) 2019

\begin{abstract}
In cases of difficult biliary cannulation, transpancreatic sphincterotomy (TPS) can be an alternative approach of biliary access. However, its success and safety profile have not been studied in detail. A systematic review and meta-analysis were performed to study the overall cannulation success and adverse events of TPS. These outcomes were also compared to other advanced cannulation methods. A systematic literature search was conducted to find all relevant articles containing data on TPS. Successful biliary cannulation and complications rates [post-ERCP pancreatitis (PEP), bleeding, and perforation rates] were compared in the pooled analyses of prospective comparative studies. The overall outcomes were calculated involving all studies on TPS. TPS was superior compared to needle-knife precut papillotomy (NKPP) and the double-guidewire method (DGW) regarding cannulation success (odds ratio [OR] 2.32; 95\% confidence interval [CI] 1.37-3.93; and OR 2.72; 95\% CI 1.30-5.69, respectively). The rate of PEP did not differ between TPS and NKPP or DGW; however, TPS (only retrospective studies were available for comparison) proved to be worse than needle-knife fistulotomy in this regard (OR 4.62; 95\% CI 1.36-15.72). Bleeding and perforation rates were similar among these advanced techniques. There were no data about long-term consequences of TPS. The biliary cannulation rate of TPS is higher than that of the other advanced cannulation techniques, while the safety profile is similar to those. However, no long-term follow-up studies are available on the later consequences of TPS; therefore, such studies are strongly needed for its full evaluation.
\end{abstract}

Keywords Cholangiopancreatography, endoscopic retrograde/adverse effects · Cholangiopancreatography, endoscopic retrograde/methods · Postoperative hemorrhage/etiology $\cdot$ Sphincterotomy, endoscopic/adverse effects $\cdot$ Sphincterotomy, endoscopic/methods

Electronic supplementary material The online version of this article (https://doi.org/10.1007/s10620-019-05640-4) contains supplementary material, which is available to authorized users.

Áron Vincze

vincze.aron@pte.hu

1 Institute for Translational Medicine, Medical School, University of Pécs, Pecs, Hungary

2 Institute of Bioanalysis, Medical School, University of Pécs, Pecs, Hungary

3 Momentum Research Group, Hungarian Academy of Sciences, University of Szeged, Szeged, Hungary

4 First Department of Medicine, University of Szeged, Szeged, Hungary

\section{Introduction}

Biliary access during endoscopic retrograde cholangiopancreatography (ERCP) is successful after a few attempts with basic cannulation methods in around $80 \%$ of the cases. The European Society of Gastrointestinal

5 Department of Oral Biology, Faculty of Dentistry, Semmelweis University, Budapest, Hungary

6 Department of Pathophysiology, University of Szeged, Szeged, Hungary

7 Division of Gastroenterology, First Department of Medicine, Medical School, University of Pécs, Ifjúság u. 13, Pecs, Hungary 
Endoscopy (ESGE) recommends guidewire-assisted cannulation over contrast material injection during the initial attempts because of the higher rate of success and a lower rate of post-ERCP pancreatitis (PEP) [1]. However, in challenging cases, the initial attempts to achieve selective biliary cannulation can fail even in the hands of experienced endoscopists. A consensus definition of difficult biliary cannulation is still lacking. The current ESGE guideline defines it as more than five contacts with the papilla while attempting to cannulate, more than 5 min spent attempting to cannulate the papilla after visualization, or more than one unintended pancreatic duct cannulation or opacification. The time limit of the standard cannulation technique is extended to $10 \mathrm{~min}$, but other aspects are identical in another new international recommendation [2]. Early use of advanced cannulation techniques is advised in these situations to prevent further papillary trauma. Two scenarios are possible in case of failed biliary access: Needle-knife precut methods or pancreatic guidewire-assisted methods can be applied if the guidewire is inserted into the pancreatic duct [1].

Pancreatic guidewire-assisted methods can be classified as single-guidewire methods (cannulation attempts, contrast material injection, or precut after leaving the guidewire in the pancreatic duct), double-guidewire technique (DGW) [3], and transpancreatic (biliary) sphincterotomy (TPS) [4]. A recent meta-analysis of randomized controlled trials showed that the DGW technique has a higher PEP rate compared to other advanced methods despite its relative "noninvasiveness" [5]. Our previous meta-analysis showed that TPS is an effective technique which provides a higher rate of successful biliary access; furthermore, its application results in lower bleeding and PEP rates when compared to needle-knife precut papillotomy (NKPP) [6].

The needle-knife precut techniques are freehand precut starting either from the papillary orifice (NKPP) or at the papillary roof (needle-knife fistulotomy, NKF). These techniques can also be applied after pancreatic guidewire or prophylactic pancreatic stents (PPS) insertion. In fact, some studies are showing better outcomes (i.e., higher success and lower complication rates) with this method compared to the freehand precut [7]. NKPP with a small incision over a pancreatic stent improves the success rate and reduces the complication rate in difficult biliary cannulations [7] or when compared to standard cannulation [8]. Some studies suggest that NKF is superior to NKPP in terms of success and complications, providing a lower PEP rate by avoiding the trauma of the orifice [9].

In the present systematic review, the efficacy and safety of the rarely used TPS technique are scrutinized further by comparing them with other frequently used advanced cannulation methods. TPS was first described by Goff et al. [4], and he published results from 51 patients with remarkable success rate and safety profile of TPS later on [10]. Since then, several case series, retrospective and prospective comparative studies, and few randomized controlled trials (RCTs) have been published. On the other hand, concerns have been raised about the long-term safety of this technique [11]. The possibility of pancreatic stenosis, as seen in the cases of therapeutic pancreatic sphincterotomies, should not be ignored [11, 12]. Here, we summarize the available evidence of the success rate, immediate, and late adverse events related to TPS in comparison with other advanced cannulation methods by executing a systematic review.

\section{Methods}

\section{Search Strategy}

A systematic literature search was conducted to find all relevant articles containing data on TPS in accordance with the PRISMA guideline [13]. The search strategy included the following terms: "transpancreatic septotomy" or "transpancreatic sphincterotomy" or "transpancreatic septostomy" or "transpancreatic precut sphincterotomy" or "pancreatic sphincterotomy" or "transpancreatic papillary septotomy" or "transpancreatic sphincter precut" or "transpancreatic duct precut" or "pancreatic sphincter precutting" or "pancreatic precut sphincterotomy" or "transpancreatic precut septotomy" or "transpancreatic precut septostomy" or "pancreatic septotomy" or "pancreatic septostomy" or "pancreatic precut" or "transpancreatic precut" or "transpancreatic." EMBASE, PubMed, Scopus, Web of Science, ProQuest, and Cochrane Library databases were searched from their inception till February 8, 2018.

\section{Inclusion Criteria}

In order to compare TPS to DGW and NKPP, only prospective studies were included. However, only retrospective data were available in the comparison of TPS-NKF, and these were also included in our analysis. Appropriate conference abstracts were also analyzed to minimize publication bias, and additional subgroup analyses excluding them were carried out to show their effects on outcomes.

Comparative and also non-comparative prospective and retrospective studies were included in the calculation of overall success and complications rate of TPS. Randomized controlled trials (RCT) and prospective and retrospective observational studies were analyzed separately (Table 4). 


\section{Study Selection and Data Collection}

Titles and abstracts of studies identified were screened by two authors (D.P. and Á.V.) independently, and then, the full-text articles were searched to identify eligible studies. Data extraction and risk of bias assessment were done independently by the authors. Peer-reviewed works and conference abstracts were included. Unpublished data were not requested from the authors. Any disagreement was resolved by discussion in plenum. Prophylactic measures to prevent PEP; furthermore, the length and results of follow-up were also collected and analyzed.

\section{Risk of Bias Assessment}

The Newcastle-Ottawa scale (NOS) was used for prospective and retrospective studies to assess risk of bias within the individual studies [14] (Table 5). Randomized controlled trials were assessed by the Cochrane Risk of Bias Tool [15] (Table 6).

\section{Statistical Methods}

Pooled odds ratios (ORs) and their 95\% confidence intervals (CIs) were calculated to compare the biliary cannulation success and PEP rates among the different cannulation techniques. Risk difference (RD) was calculated to compare the bleeding and perforation rates in order to avoid overestimation since OR or RR calculations would exclude those studies where zero events were reported. The random-effect model of DerSimonian and Laird [16] was used in meta-analysis. Subgroup analyses excluding studies with sequential designs and that reported only in an abstract format were also carried out. Sensitivity analyses were carried out using four types of summary statistics (RR [risk ratio] vs. OR vs. RD vs. Peto's OR) and two types of meta-analytical models (fixed vs. random effects) to test the robustness of our findings [17]. Heterogeneity was tested with two methods, namely the Cochrane's $Q$ and the $I^{2}$ statistics. The $Q$ test was computed by summing the squared deviations of each study's estimate from the overall meta-analysis estimate; $P$ values were obtained by comparing the statistical results with a $\chi^{2}$ distribution with $k-1$ degrees of freedom (where $k$ was the number of studies). A $P$ value of less than 0.1 was considered suggestive of significant heterogeneity. The $I^{2}$ statistic represents the percentage of the total variability across studies that is due to heterogeneity, i.e., $I^{2}$ value between 0 and $40 \%$ indicates low, 30-60\% moderate, 50-90\% substantial, and $75-100 \%$ considerable heterogeneity, based on Cochrane Handbook for Systematic Reviews of Interventions [17]. Publication bias was planned to be examined by visual inspection of funnel plots and the Egger's method [18]. Meta-analytical calculations were done with Review Manager (RevMan) computer program (version 5.3, Copenhagen: The Nordic Cochrane Centre, The Cochrane Collaboration, 2014).

\section{Results}

\section{Study Selection}

Altogether, 2787 records were identified during database search: 510 in EMBASE, 339 in PubMed, 968 in Scopus, 255 in Web of Science, 544 in ProQuest, and 171 in Cochrane Library, respectively. The latest search was run on February 8, 2018, and finally, 33 relevant studies were included in the qualitative synthesis, while data from 14 studies were extracted for the meta-analysis (Fig. 1).

\section{Characteristics of Studies Included}

Characteristics of the included studies with the applied PEP prophylaxis (Table 1), the definitions of difficult biliary access and the endoscopists/centers experience (Table 2), and the late adverse events are summarized in Table 3.

Three RCTs [19-21] and two prospective observational studies [22, 23] compared TPS and DGW. One of them was only available in abstract form [19]. Two of them used a sequential design [22, 23], applying TPS only after DGW, as a rescue technique.

Two RCTs [24, 25] and three prospective observational studies [22, 23, 26] provided data on the comparison of TPS vs. NKPP, two of them with sequential design [22, 23]. New prospective studies were not identified after our previous meta-analysis; however, we conducted further sensitivity and subgroup analyses in this comparison [6].

Comparison of TPS and NKF was not found in any prospective studies; four retrospective studies (two of them only in abstract form) were identified and analyzed to synthesize available comparative evidence [9, 27-29].

Two prospective case series of TPS without relevant comparisons to other advanced cannulation methods [30, 31 ] and, additionally, 23 retrospective observational studies with reported outcome data were included in the pooled analyses of overall outcomes of TPS [4, 9, 10, 27-29, 32-48] (Table 4). 
Fig. 1 Flow diagram of literature search

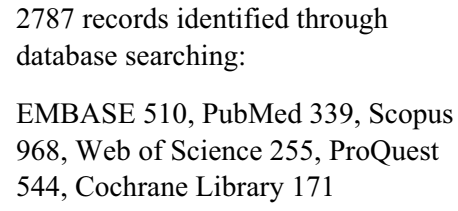

EMBASE 510, PubMed 339, Scopus 968, Web of Science 255, ProQuest 544, Cochrane Library 171
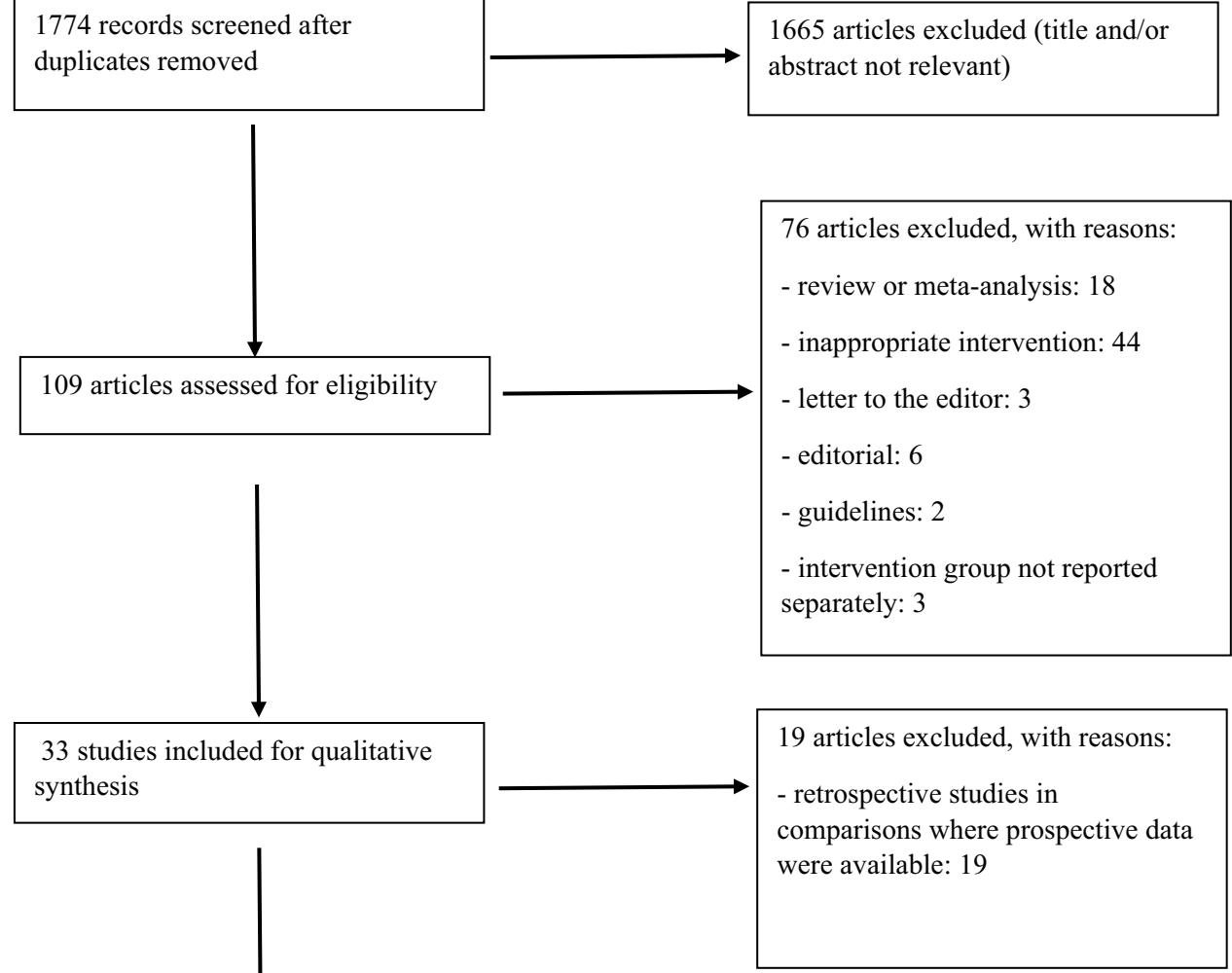

1665 articles excluded (title and/or abstract not relevant)

76 articles excluded, with reasons:

- review or meta-analysis: 18

- inappropriate intervention: 44

- letter to the editor: 3

- editorial: 6

- guidelines: 2

- intervention group not reported separately: 3

14 studies included in quantitative synthesis (meta-analysis)

\section{Methodological Quality and Risk of Bias Assessment}

The risk of bias in the prospective (not RCTs) and the four retrospective studies included in the meta-analyses was analyzed with the NOS (Table 5). In most of the full-text studies, baseline characteristics of cohorts were reported with comparable, homogeneous groups. Technical details of interventions were thoroughly reported; all full-text studies defined precut methods appropriately. On the other hand, definitions of adverse outcomes somewhat varied; however, most studies used the consensus definitions [49]. The appropriate length of follow-up is questionable in the cases of late adverse events, and only one prospective study reported the length of follow-up as longer than 30 days [30]. The abstracts contained limited information about the abovementioned details; therefore, they carry an unclear risk of bias. 
Table 1 Characteristics of the studies included in the meta-analysis with the prophylactic measures to prevent post-ERCP pancreatitis (PEP)

\begin{tabular}{|c|c|c|c|c|c|c|}
\hline Study & Study design & Comparison & $\begin{array}{l}\text { Sequen- } \\
\text { tial } \\
\text { design }\end{array}$ & Form of publication & PPS use & $\begin{array}{l}\text { Pharmacologic pre- } \\
\text { vention }\end{array}$ \\
\hline Cha et al. [19] & RCT & DGW versus TPS & No & Abstract & NR & NR \\
\hline Sugiyama et al. [20] & RCT & DGW versus TPS & No & Full text & In all cases & Nafamostat \\
\hline Yoo et al. [21] & RCT & DGW versus TPS & No & Full text & No & No \\
\hline Kim et al. [22] & Prospective & $\begin{array}{l}\text { DGW versus TPS } \\
\text { versus NKPP }\end{array}$ & Yes & Full text & $\begin{array}{l}2 / 27(7 \%) \text { in DGW } \\
\text { group, } 25 / 38(66 \%) \\
\text { in TPS group, } \\
P<0.001\end{array}$ & No \\
\hline Zou et al. [23] & Prospective & $\begin{array}{l}\text { DGW versus TPS } \\
\text { versus NKPP }\end{array}$ & Yes & Full text & $\begin{array}{l}\text { 14/63 }(22 \%) \text { in all } \\
\text { patients compared, } \\
\text { not reported sepa- } \\
\text { rately in DGW/TPS } \\
\text { groups }\end{array}$ & No \\
\hline Catalano et al. [24] & RCT & NKPP versus TPS & No & Full text & PPS in some patients & No \\
\hline Zang et al. [25] & RCT & NKPP versus TPS & No & Full text & No & No \\
\hline Espinel-Diez [26] & Prospective & NKPP versus TPS & No & Full text & No & No \\
\hline Horiuchi et al. [9] & Retrospective & NKF versus TPS & No & Full text & No & No \\
\hline Katsinelos et al. [27] & Retrospective & $\begin{array}{l}\text { NKPP versus NKF } \\
\text { versus TPS }\end{array}$ & No & Full text & PPS in some patients & $\begin{array}{l}\text { Diclofenac and } \\
\text { somatostatin in some } \\
\text { patients }\end{array}$ \\
\hline Lee et al. [28] & Retrospective & NKF versus TPS & No & Abstract & No & Protease inhibitor \\
\hline Wen et al. [29] & Retrospective & NKF versus TPS & No & Abstract & NR & NR \\
\hline Kahaleh et al. [30] & Prospective & No & No & Full text & $\begin{array}{l}29 / 116(25 \%) \text { of all } \\
\text { cases }\end{array}$ & NR \\
\hline Weber et al. [31] & Prospective & No & No & Full text & No & NR \\
\hline
\end{tabular}

$P P S$ prophylactic pancreatic stent, $R C T$ randomized controlled trial, $D G W$ double-guidewire cannulation, $T P S$ transpancreatic biliary sphincterotomy, NKPP needle-knife precut papillotomy, $N K F$ needle-knife fistulotomy, $N R$ not reported

In case of RCTs, the Cochrane Risk of Bias Tool was used (Table 6). Only one study [21] reported the method of randomization and the method of ensuring allocation concealment. Blinding in studies of endoscopic interventions at participant and personnel level is difficult to execute and therefore could not be expected. However, blinded late outcome assessment (PEP, late bleeding, perforation) could be arranged more easily. Nevertheless, none of the studies reported blinding of any kind. Three out of five RCTs did not report the rate of cholangitis; therefore, this outcome could not be analyzed [19, 24, 25]. One RCT was only published in abstract form which makes the data quality questionable; consequently, this study carries a high risk of bias [19].

Publication bias could not be reliably assessed based on funnel plots or by the Egger's method because of the small number of included studies. According to the Cochrane Handbook, funnel plots and other statistical tests are not advised to assess small study effect and publication bias under ten studies per analysis $[17,18,50]$.

\section{Endoscopists' Experience and Centers' Case Volumes in the Prospective Studies}

Most of the prospective studies reported endoscopists' experience in yearly case numbers, some in lifetime ERCP numbers, too. Based on the reported numbers, all endoscopists performed more than 200 ERCPs/year. In one study, the caseload of the endoscopists exceeded 500 ERCPs annually [30]. Trainee participation was not reported in any of the studies. Most of the centers reported high-volume ERCPs (even above 1000 procedures/year [23, 24]), only one study [9] reported lower numbers (<300 ERCPs/year), while no information was found about center or endoscopist caseload in one study [29] (Table 2).

\section{Biliary Cannulation Success Rate}

TPS showed superiority in success rate compared to DGW (OR 2.72; 95\% CI 1.30-5.69; 176 and 235 patients, 


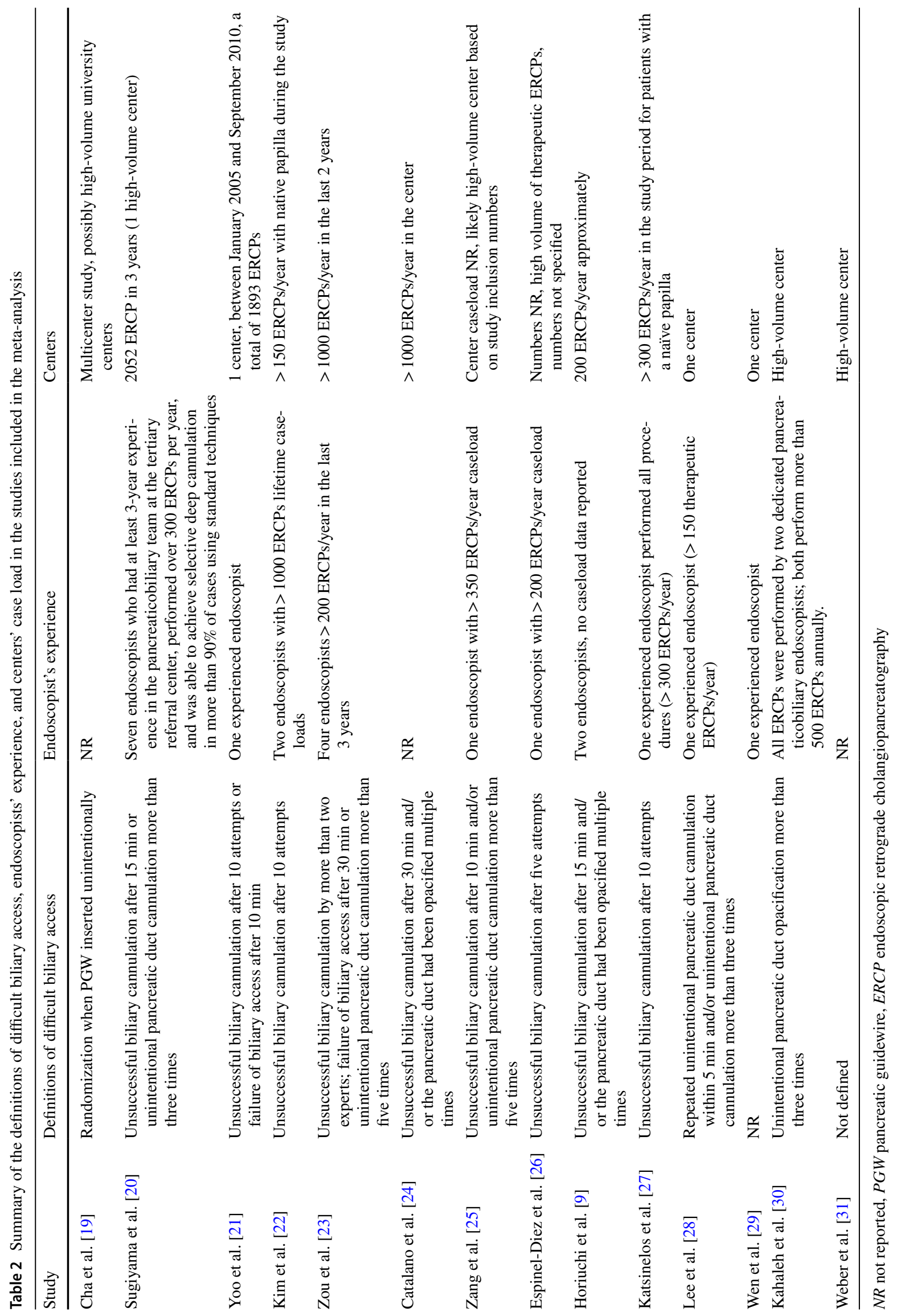


Table 3 Late adverse events in the prospective studies, where longer-term follow-ups were reported

\begin{tabular}{lllllc}
\hline Study & Study design & Length of follow-up & Type & Complications & PD stricture \\
\hline Kim et al. [22] & Prospective, observational & NR & NR & No & $\begin{array}{c}\text { No chronic pancreatitis } \\
\text { or ductitis from PD } \\
\text { stenting }\end{array}$ \\
Catalano et al. [24] & RCT & NR & $\begin{array}{c}\text { Telephone contact and office } \\
\text { visits }\end{array}$ & No & No \\
Kahaleh et al. [30] & Prospective, observational & $\begin{array}{c}\text { Median follow-up } \\
\text { was 5 months } \\
(2-35)\end{array}$ & $\begin{array}{c}\text { Clinic visit and/or telephone } \\
\text { interview by a nurse }\end{array}$ & No & No \\
\hline
\end{tabular}

Studies without follow-up data are not shown

$R C T$ randomized controlled trial, $P D$ pancreatic duct, $N R$ not reported

respectively; $I^{2}=50 \%$ ) (Fig. 2a) and NKPP (OR 2.32; 95\% CI $1.37-3.93 ; 292$ and 260 patients, respectively; $I^{2}=7 \%$ ) (Fig. 2b). The success rate of TPS and NKF did not differ (OR 1.38; 95\% CI 0.32-5.96; 295 and 141 patients, respectively; $I^{2}=22 \%$ ) (Fig. 2c).

In the TPS versus DGW comparison of cannulation success rates, no significant difference was detected between the two methods if only RCTs were included (OR 3.02; 95\% CI $0.73-12.59$; 113 and 107 patients, respectively; $I^{2}=69 \%$ ), probably because of the greater confidence intervals of the results. On the other hand, subgroup analysis of full-text studies found the superiority of TPS over DGW with regard to cannulation success rate (Suppl. Figure 1).

The overall success rate of TPS in prospective studies was $89.7 \%$ (564/629). The success rate was the same if all studies were analyzed $(89.6 \%, 2343 / 2615)$, as well as the separate analysis of RCTs resulted in similarly high value $(91.7 \%$, 199/217) (Table 4).

\section{Post-ERCP Pancreatitis}

No significant difference was found between the TPS versus DGW (OR 0.72; 95\% CI 0.24-2.10; 151 and 134 patients, respectively; $I^{2}=55 \%$ ) (Fig. $\left.3 a\right)$ and TPS versus NKPP (OR 1.63 ; 95\% CI 0.48-5.47; 265 and 242 patients, respectively; $I^{2}=57 \%$ ) (Fig. 3b) comparisons. However, the TPS technique showed a higher PEP rate compared to NKF method (OR 4.62; 95\% CI 1.36-15.72; 295 and 141 patients, respectively; $I^{2}=16 \%$ ) (Fig. 3c).

If we excluded abstracts from the NKF versus TPS comparison, the significant difference disappeared (OR 3.49; 95\% CI $0.20-62.21 ; 86$ and 115 patients, respectively; $I^{2}=63 \%$ ) and expectedly, a wide confidence interval could be seen (Suppl. Figure 2). In the other subgroups, no differences were found when sequential studies or abstracts were omitted from the analyses. Inclusion of RCTs only did not result any change in significance regarding TPS versus DGW and TPS versus NKPP comparisons.
The overall PEP rate of TPS was $8.1 \%(49 / 604)$ in prospective studies, $7.1 \%$ (183/2590) in all studies, and 7.4\% (16/217) in RCTs (Table 4).

\section{Prophylactic Pancreatic Stent and Nonsteroid Anti-inflammatory Suppository Use}

Only one recently published study used PPS in all patients undergoing TPS [20], while all the others reported no or only some PPS implantation in the TPS cases (Table 1). Pharmacologic prevention of PEP was applied in three studies [20, 27, 28]; however, the recommended nonsteroid antiinflammatory drug (NSAID) suppositories were not used or not reported in any of the studies included in the metaanalyses (Table 1).

\section{Bleeding}

The pooled analysis did not show any difference in bleeding rate when TPS was compared to DGW (risk difference [RD] $0.01 ; 95 \% \mathrm{CI}-0.03$ to $0.05 ; 109$ and 95 patients, respectively; $I^{2}=0 \%$ ) (Fig. 4a), NKPP (RD $-0.00 ; 95 \%$ CI -0.04 to $0.03 ; 268$ and 239 patients, respectively; $\left.I^{2}=20 \%\right)$ (Fig. 4b), and NKF (RD 0.00; 95\% CI -0.03 to $0.03 ; 295$ and 141 patients, respectively; $I^{2}=0 \%$ ) (Fig. $4 \mathrm{c}$ ).

Subgroup analyses did not alter the findings of bleeding rates significantly.

The overall bleeding rate of TPS was $3.4 \%$ (19/562) in prospective studies, $2.0 \%(50 / 2548)$ in all studies, and $1.7 \%$ (3/175) in RCTs (Table 4).

\section{Perforation}

Perforation rates did not differ when comparing TPS versus DGW (RD $-0.01 ; 95 \% \mathrm{CI}-0.04$ to $0.03 ; 109$ vs. 95 ; $\left.I^{2}=0 \%\right)$ (Fig. 5a), TPS versus NKPP (RD $-0.00 ; 95 \%$ CI -0.02 to $0.01 ; 267$ and 240 patients, respectively; $I^{2}=0 \%$ ) 


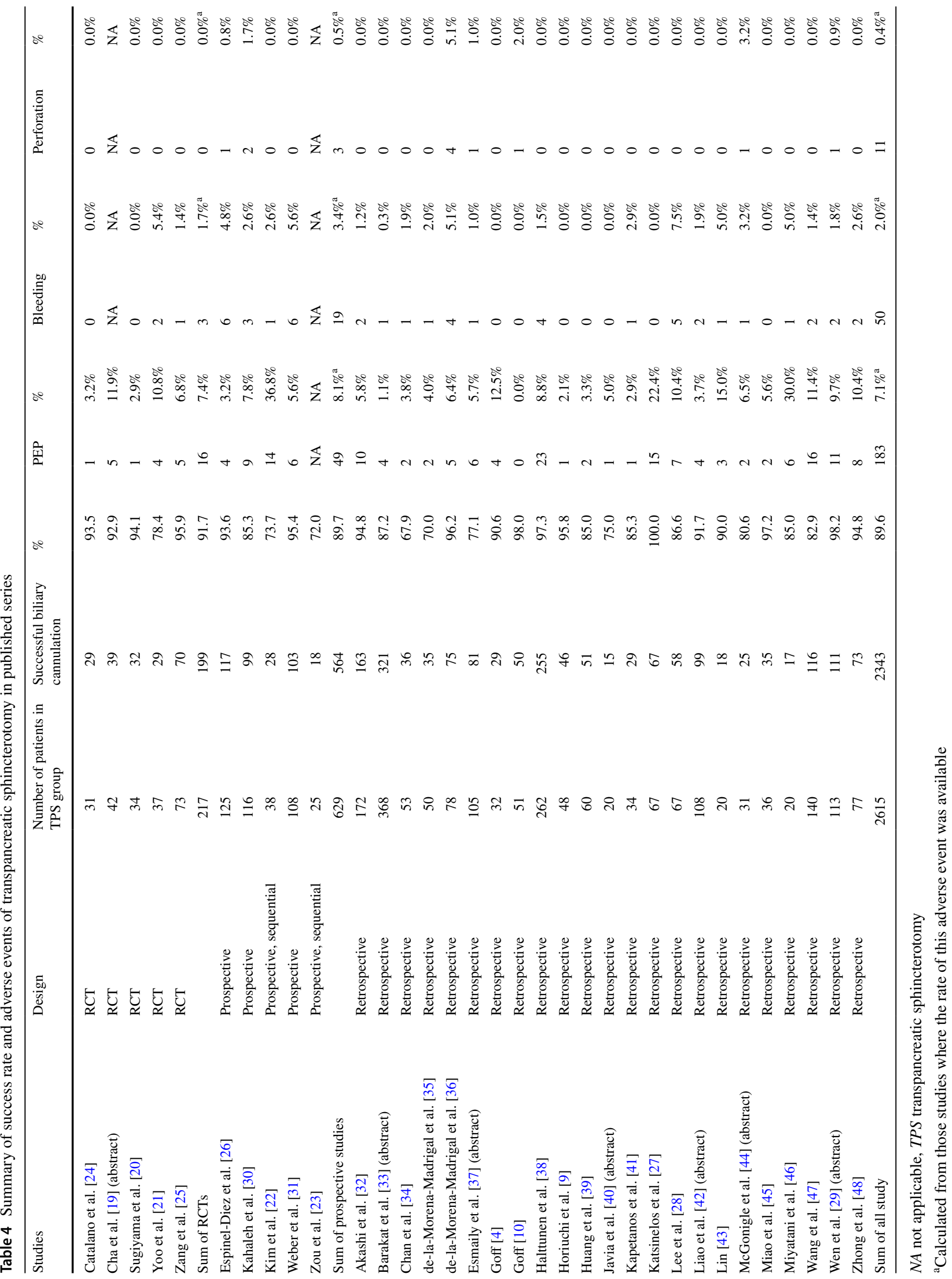


Table 5 Risk of bias assessment of prospective, non-randomized, and retrospective studies with the Newcastle-Ottawa scale

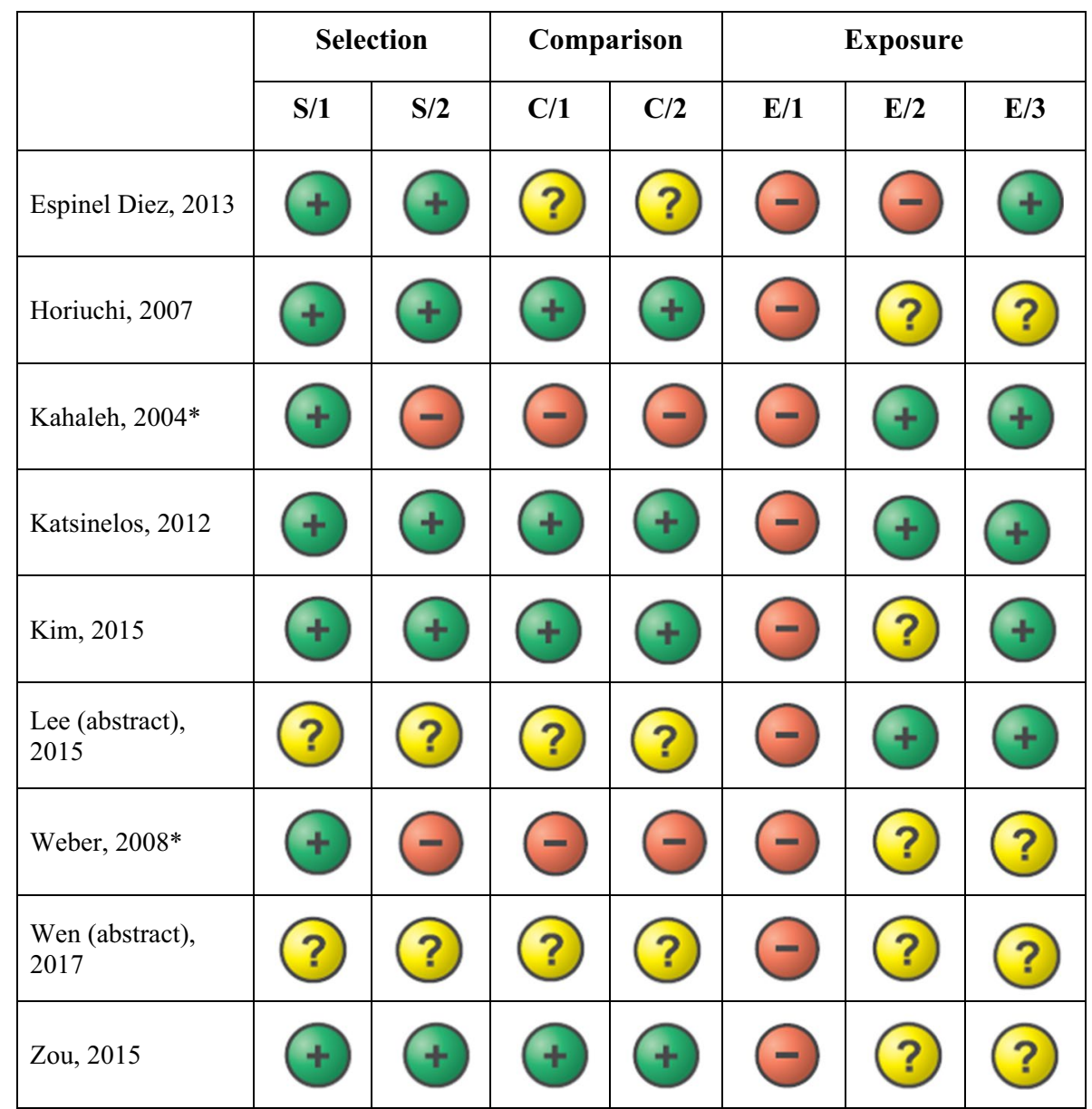

S/1: Representativeness of the exposed cohort (transpancreatic sphincterotomy group compared to advanced cannulation technique group); S/2: Selection of the non-exposed cohort (advanced cannulation technique group); C/1: Comparability of cohorts on the basis of similar indications of procedure; $\mathrm{C} / 2$ : Comparability of cohorts on the basis of age; E/1: Assessment of outcome (were blinded assessment executed?); E/2: Was follow-up long enough? (longer than 14 days); E/3: Adequacy of follow-up of cohorts (is any attrition of patients present?) Two studies are not comparing TPS to another advanced cannulation technique and are marked with an asterisk

(Fig. 5b), and TPS versus NKF (RD 0.00; 95\% CI -0.02 to 0.03; 295 and 141 patients, respectively; $I^{2}=0 \%$ ) (Fig. 5c).

Subgroup analyses did not alter the findings in perforations rates significantly.

The overall perforation rate was $0.5 \%$ (3/562) in prospective studies, $0.4 \%(11 / 2548)$ in all studies, while $0 \%(0 / 175)$ in RCTs (Table 4).

\section{Sensitivity and Subgroup Analyses}

Application of other meta-analytical models (fixed-effect vs. random-effect analysis) and summary statistics (OR vs. RR vs. RD vs. Peto's OR) did not affect the outcomes significantly in the main analyses; thus, our conclusions remain unaltered (Suppl. Table 1).
However, subgroup analyses excluding non-RCTs, sequential trials, and studies only available in an abstract form altered significantly some results (i.e., success rate in TPS vs. DGW and PEP rate in TPS vs. NKF comparisons, respectively) (Suppl. Table 2, Figs. 1 and 2).

\section{Follow-Up}

Pancreatic duct stricture or chronic pancreatitis could potentially develop after pancreatic sphincterotomy; therefore, a longer follow-up period is needed to detect these adverse outcomes [11]. Small caliber pancreatic stents could rarely cause pancreatic ductal changes in long term (1 month or longer) [51, 52]. Only one prospective study, a case series with 116 patients, reported a median 5-month follow-up 
Table 6 Risk of bias assessment of RCTs with the Cochrane Collaboration risk of bias tool

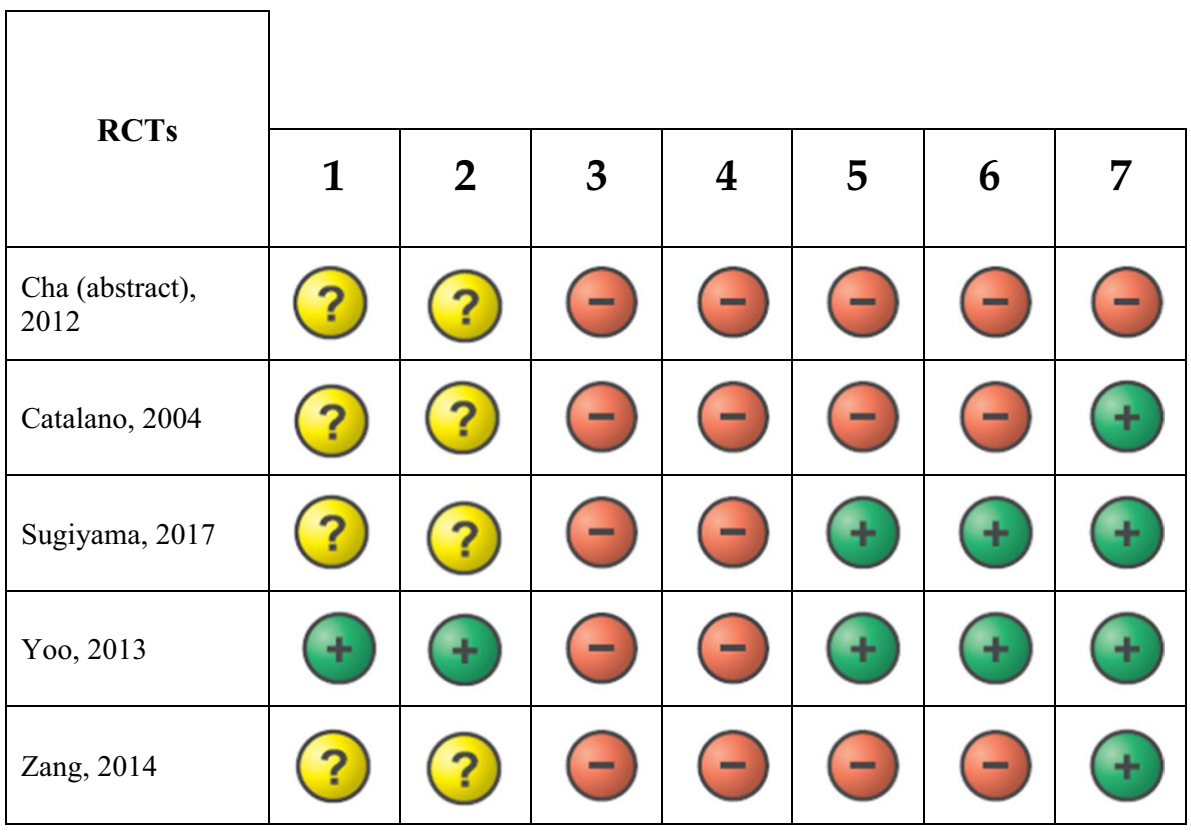

1: Random sequence generation; 2: allocation concealment; 3: blinding of participants and personnel; 4: blinding of outcome assessment; 5 : incomplete outcome data; 6 : selective reporting; 7: other bias (range 2-35) with no late adverse events [30]. Another paper similarly did not report late chronic pancreatitis or ductitis from PPS; no strictures were described during longer, however not specified, follow-up [22] (Table 3). A few retrospective studies also published longer-term results: Miao et al. [45] reported no stricture after 4 months of follow-up period, while Barakat et al. [33] found no late stricture formation after an unknown length of "long-term" follow-up.

\section{Discussion}

This systematic review and meta-analysis show that TPS could be equally successful or even slightly better in the setting of difficult biliary access compared to other advanced cannulation methods. Analyzing only the prospective studies with regard to cannulation success rates TPS seems superior to DGW and NKPP, while TPS and NKF are equally effective. DGW and NKPP carry a similar risk of PEP compared to TPS; however, PEP occurs more frequently with TPS than with NKF. No difference in bleeding and perforation rates was found when comparing TPS to the other advanced cannulation methods.

Prospective observational studies and RCTs were analyzed whenever it was possible to gain the best evidence. Between-study heterogeneity was low or moderate in most analyses, making our conclusions more accurate. Sensitivity analyses and application of different statistical and meta-analytical methods did not reveal any significant changes in the main associations. However, subgroup analyses excluding sequential studies revealed that the significant difference disappeared in some analyses, thereby weakening our conclusion in the findings of success rate of TPS versus DGW and PEP rate in TPS versus NKF. However, this is most probably the result of the low case numbers, leading to imprecision and wider confidence intervals.

Exceptionally low cannulation rates (as low as 72\%) and high PEP rates (36.8\%) were seen in the sequential studies (Table 4) that probably could be explained by the previous DGW attempts causing papillary trauma and consequential edema. Our experience also shows that TPS after papillary trauma induced by precut results low rate of biliary access, while it is highly successful if applied primarily [53]. Based on these considerations, we recommend the TPS technique in the early phase of difficult biliary access when pancreatic guidewire insertion reached unintentionally.

The overall cannulation success rate of TPS is close to $90 \%$ in all studies and also in subgroups by different study designs, which makes this pancreatic guidewire-assisted method a good alternative to DGW and other advanced cannulation methods. The overall biliary cannulation success 


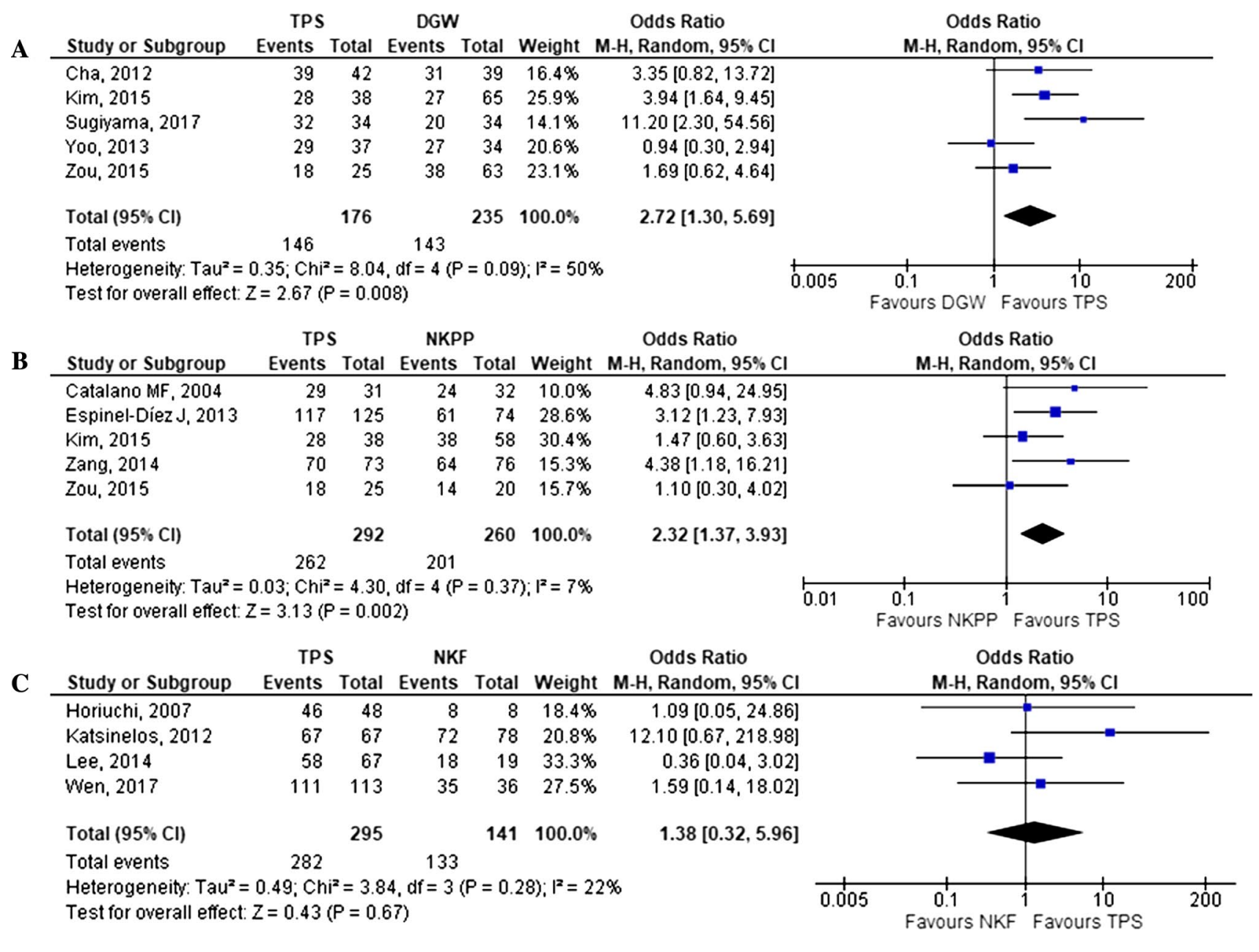

Fig. 2 a Forest plot of cannulation success rate of transpancreatic sphincterotomy (TPS) versus double-guidewire technique (DGW) in prospective studies; b comparison of cannulation success rate of TPS versus needle-knife precut papillotomy (NKPP) in prospective stud-

rate of DGW was only $61 \%$ in the studies where it was compared to TPS (Fig. 2a). Furthermore, a meta-analysis of seven RCTs with DGW showed that successful biliary cannulation was achieved only in $82 \%$ of cases [5]. NKPP is also a frequently used method in cases of difficult biliary access. The average cannulation success rate of NKPP was approximately $80 \%$ (647/812) in all NKPP studies and 77\% (201/260) in prospective studies according to our previous meta-analysis [6].

PEP rate of TPS is similar to other advanced cannulation methods $(7.1 \% ; 183 / 2590 ; 0-30 \%$, Table 4). NKPP seems comparable to TPS with its $8.8 \%$ (70/794) overall PEP rate measured in our previous meta-analysis [6]. NKF, however, could be better to avoid PEP (Fig. 3c). With the uniform use of PPS and NSAID suppositories ies; c comparison of cannulation success rate of TPS versus needleknife fistulotomy (NKF) in available comparative retrospective studies

in all TPS cases, a PEP rate might be even lower [20,48] as the significant protective effect of PPS has been well proven. Importantly, its insertion should not be problematic since the guidewire is already in the pancreatic duct while performing TPS.

Bleeding rate of TPS is in the range of $2-4 \%$, which is comparable to the widely accepted and frequently used needle-knife precut techniques (4\%; 30/745 of NKPP cases) [6]. The rate of perforation was around $0.5 \%$ which is remarkably low for a precut technique, and no difference was found in this respect between TPS and the other advanced cannulation techniques.

There are several limitations of our analyses. First of all, the low number of prospective studies with only small cohorts of patients weakens the conclusions. Sequential 
$\begin{array}{cccc}\text { TPS } & \text { DGW } & \text { Odds Ratio } \\ \text { A Study or Subgroup } & \text { Events Total Events Total Weight } & \text { M-H, Random, } 95 \% \mathrm{Cl}\end{array}$

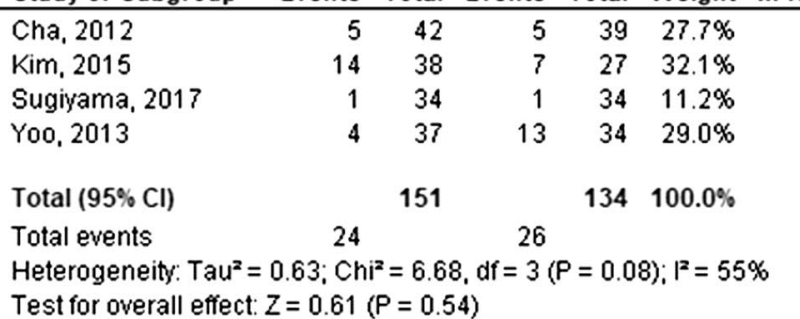

$0.92[0.24,3.45]$

$1.67[0.56,4.93]$

$1.00[0.06,16.67]$

$0.20[0.06,0.68]$

$0.72[0.24,2.10]$

Odds

M-H, Random, $95 \% \mathrm{Cl}$

\begin{tabular}{|c|c|c|c|c|c|c|c|c|c|}
\hline \multirow{2}{*}{ Study or Subgroup } & \multicolumn{2}{|c|}{ TPS } & \multicolumn{2}{|c|}{ NKPP } & \multicolumn{2}{|r|}{ Odds Ratio } & & \multirow{2}{*}{\multicolumn{2}{|c|}{$\begin{array}{c}\text { Odds Ratio } \\
\text { M-H, Random, } 95 \% \mathrm{Cl}\end{array}$}} \\
\hline & Events & Total & Events & Total & Weight & M-H, Random, $95 \% \mathrm{Cl}$ & & & \\
\hline Catalano MF, 2004 & 1 & 29 & 4 & 34 & $17.8 \%$ & $0.27[0.03,2.54]$ & & & \\
\hline Espinel-Diez J, 2013 & 4 & 125 & 1 & 74 & $18.2 \%$ & $2.41[0.26,22.01]$ & & & \\
\hline Kim, 2015 & 14 & 38 & 6 & 58 & $33.8 \%$ & $5.06[1.73,14.76]$ & & & \\
\hline Zang, 2014 & 5 & 73 & 5 & 76 & $30.3 \%$ & $1.04[0.29,3.77]$ & & & \\
\hline Total $(95 \% \mathrm{Cl})$ & & 265 & & 242 & $100.0 \%$ & $1.63[0.48,5.47]$ & & & \\
\hline Total events & 24 & & 16 & & & & & & \\
\hline $\begin{array}{l}\text { Heterogeneity: } \text { Tau }^{2}= \\
\text { Test for overall effect: }\end{array}$ & $\begin{array}{l}84: \mathrm{Chi}^{2} \\
=0.78(\mathrm{P}\end{array}$ & $\begin{array}{l}=6.98, \\
=0.43\end{array}$ & $d f=3(P$ & $=0.07)$ & $; 1^{2}=57 \%$ & & 0.0 & $\begin{array}{l}1 \\
0.1 \\
\text { Favours TPS }\end{array}$ & $\begin{array}{lr}1 & 10 \\
\text { Favours NKP }\end{array}$ \\
\hline
\end{tabular}

C

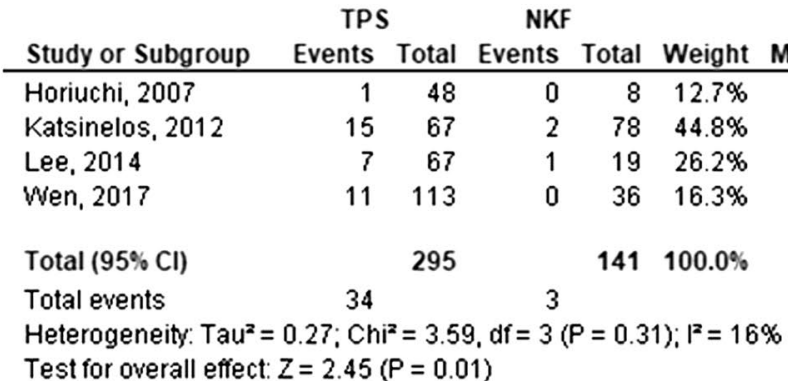

Odds Ratio

Odds Ratio

M-H, Random, $95 \% \mathrm{Cl}$

$0.54[0.02,14.31)$

$10.96[2.40,49.97]$

$2.10[0.24,18.22]$

$8.19[0.47,142.52]$

$4.62[1.36,15.72]$
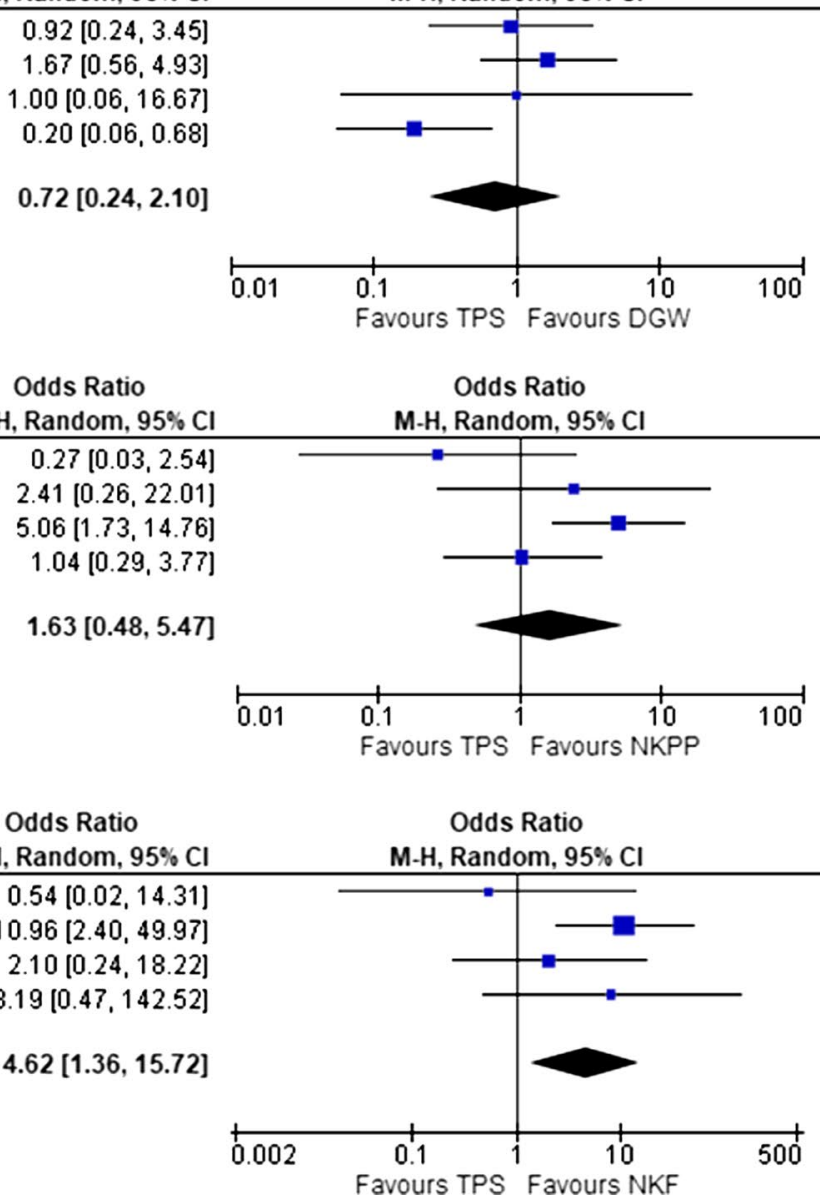

Fig. 3 a Forest plot of post-ERCP pancreatitis (PEP) rate of transpancreatic sphincterotomy (TPS) versus double-guidewire technique (DGW) in prospective studies; b comparison of PEP rate of TPS

studies were also included which could alter our results. However, in the comparison of DGW or NKPP vs. TPS, sequential designs could affect the TPS cannulation success and adverse event rate only to the worse due to the prolonged cannulation attempt and greater trauma of the papilla. The lack of information on the use of effective preventive methods (PPS, NSAID suppositories) undermines the assessment of PEP rates. New studies are lacking in this field with the consistent use of PPS and NSAID suppositories. It should be noted, however, that the PEP rate was only $1.1 \%$ in the study of Sugiyama et al. [20], where all patients received PPS after TPS, compared to the rate of $7.1 \%$ pooled from all studies where most patients did not versus needle-knife precut papillotomy (NKPP) in prospective studies; c comparison of PEP rate of TPS versus needle-knife fistulotomy (NKF) in available comparative retrospective studies

have PPS. Besides that, the definitions of outcomes were not standardized in all cases. Nonetheless, most prospective studies used the consensus definitions [49]. Publication bias cannot be ruled out due to the low number of studies per analysis.

The possible benefit of TPS over the freehand precut techniques is that it is a wire-assisted method, with better control of the cut. For that reason, it could be appealing in those situations, where the papillary tract is smaller, or the position of the scope is unstable. Furthermore, the PPS insertion could also be easily achieved after the precut, since the guidewire is already inserted into the pancreatic duct. An additional benefit is that the sphincterotome does not need 


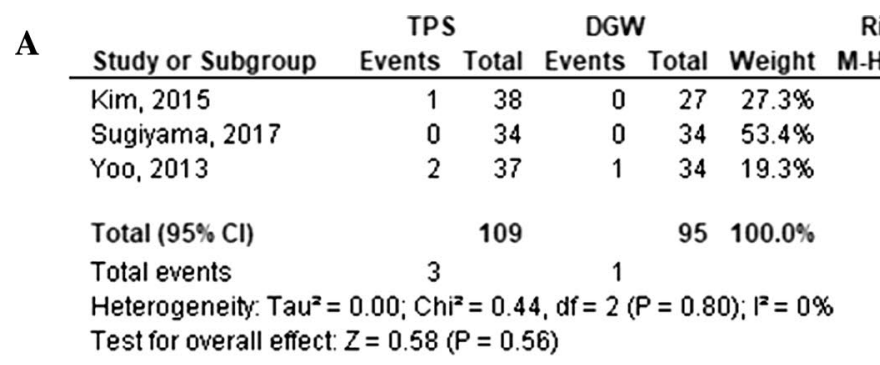

Risk Difference Risk Difference

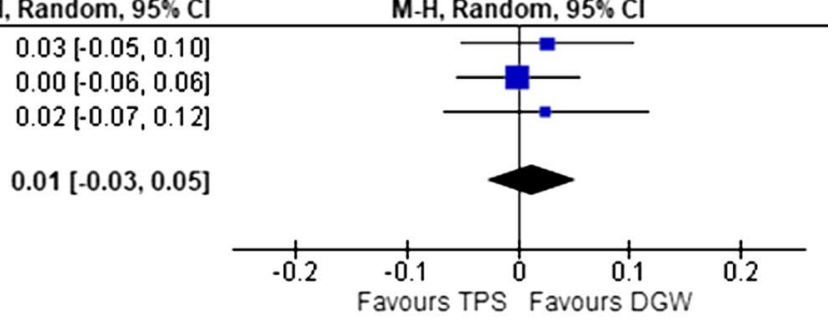

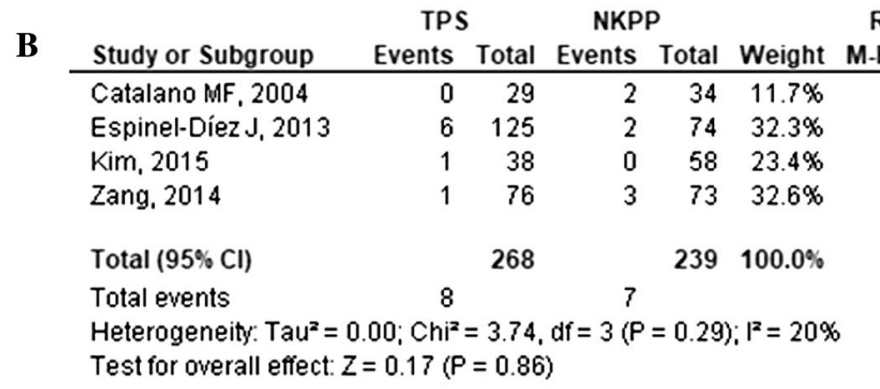

Risk Difference Random, 95\% Cl $-0.06[-0.16,0.04]$ $0.02[-0.03,0.07]$ $0.03[-0.04,0.09]$ $-0.03[-0.08,0.02]$

$-0.00[-0.04,0.03]$ Heterogeneity: $\mathrm{Tau}^{2}=0.00 ; \mathrm{Chi}^{2}=3.74, \mathrm{df}=3(\mathrm{P}=0.29) ; \mathrm{I}^{2}=20 \%$
Test for overall effect: $Z=0.17(P=0.86)$

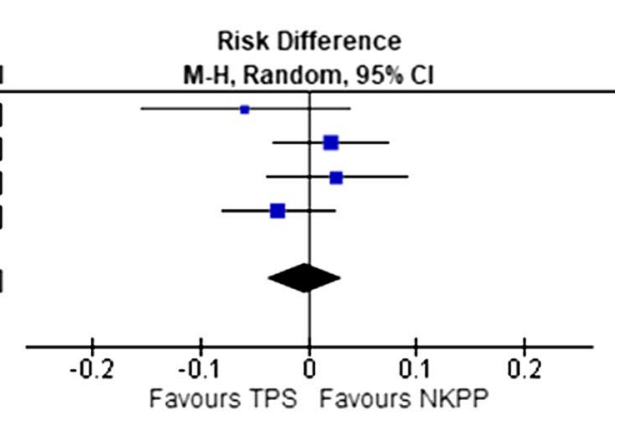

\begin{tabular}{|c|c|c|c|c|c|c|}
\hline \multirow{2}{*}{\multicolumn{2}{|c|}{ Study or Subgroup }} & \multicolumn{2}{|c|}{ TPS } & \multicolumn{2}{|c|}{ NKF } & \multirow[b]{2}{*}{ Weight } \\
\hline & & Events & Total & Events & Total & \\
\hline & Horiuchi, $200 ?$ & 0 & 48 & 0 & 8 & $3.9 \%$ \\
\hline & Katsinelos, 2012 & 0 & 67 & 2 & 78 & $47.2 \%$ \\
\hline & Lee, 2014 & 5 & 67 & 1 & 19 & $6.4 \%$ \\
\hline & Wen, 2017 & 2 & 113 & 0 & 36 & $42.6 \%$ \\
\hline & Total $(95 \% \mathrm{CI})$ & & 295 & & 141 & $100.0 \%$ \\
\hline & Total events & 7 & & 3 & & \\
\hline & $\begin{array}{l}\text { Heterogeneity. Tau } \\
\text { Test for overall effe }\end{array}$ & $\begin{array}{l}.00 ; \mathrm{Ch} \\
=0.21\end{array}$ & $\begin{array}{l}z=2.00 \\
P=0.8\end{array}$ & 0, $d f=3$ & 0 . & $I^{2}=0 \%$ \\
\hline
\end{tabular}

Risk Difference $\mathrm{M}-\mathrm{H}$, Random, $95 \% \mathrm{Cl}$ $0.00[-0.15,0.15]$ $-0.03[-0.07,0.02]$ $0.02[-0.10,0.14]$ $0.02[-0.03,0.06]$

$-0.00[-0.03,0.03]$

Heterogeneity: $\mathrm{Tau}^{2}=0.00 ; \mathrm{Chi}^{2}=2.00$,
Test for overall effect: $Z=0.21(P=0.84)$

Fig. 4 a Forest plot of bleeding rate after transpancreatic sphincterotomy (TPS) versus double-guidewire technique (DGW) in prospective studies; $\mathbf{b}$ comparison of bleeding rate after TPS versus needle-knife

precut papillotomy (NKPP) in prospective studies; $\mathbf{c}$ comparison of bleeding rate after TPS versus needle-knife fistulotomy (NKF) in available comparative retrospective studies

to be changed for the precut. In the unfortunate cases, when TPS fails, additional needle-knife incision could be helpful to reach deep biliary cannulations and might be used as salvage technique in appropriate situations.

The late adverse events of TPS, e.g., pancreatic duct stricture and chronic pancreatitis [11], could not be assessed properly because only one prospective study reported a longer-term (more than 30-day) follow-up with no late

adverse events [30]. We think that follow-up studies should be extended up to 1 year or longer to detect late adverse events, e.g., pancreatic duct stricture formation or the development of chronic pancreatitis.

These findings show the short-term safety and efficacy of TPS and also highlight the necessity of long-term follow-up studies after precut papillotomy. 
A

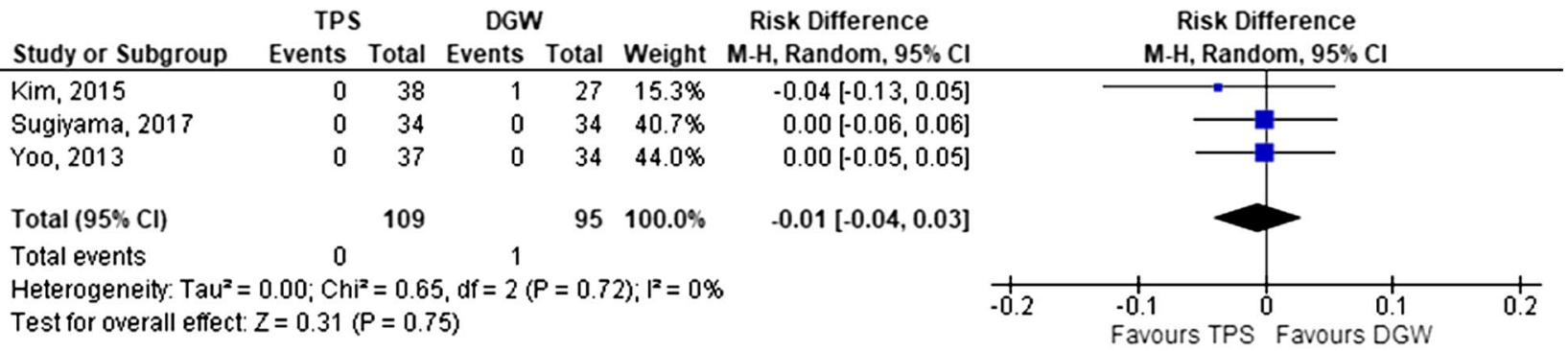

B

TPS NKPP

Risk Difference

Risk Difference

Study or Subgroup

Events Total Events Total Weight $\mathrm{M}-\mathrm{H}$, Random, $95 \% \mathrm{Cl}$

M-H, Random, $95 \% \mathrm{Cl}$

$\begin{array}{lrrrrr}\text { Catalano MF, 2004 } & 0 & 31 & 0 & 32 & 9.5 \% \\ \text { Espinel-Díez J, 2013 } & 1 & 125 & 2 & 74 & 21.1 \% \\ \text { Kim } 2015 & 0 & 38 & 0 & 58 & 18.9 \%\end{array}$

Kim, 2015

$0 \quad 73$

$0.00[-0.06,0.06]$

$-0.02[-0.06,0.02]$

$0.00[-0.04,0.04]$

Zang, 2014

267

$0 \quad 76 \quad 50.6 \%$

$0.00[-0.03,0.03]$

Total $(95 \% \mathrm{Cl})$

$1 \quad 2$

Total events

$240 \quad 100.0 \%$

Heterogeneity. Tau $^{2}=0.00 ; \mathrm{Chi}^{2}=0.80, \mathrm{df}=3(\mathrm{P}=0.85) ; \mathrm{I}^{2}=0 \%$

Test for overall effect: $Z=0.43(P=0.67)$

$-0.00[-0.02,0.01]$

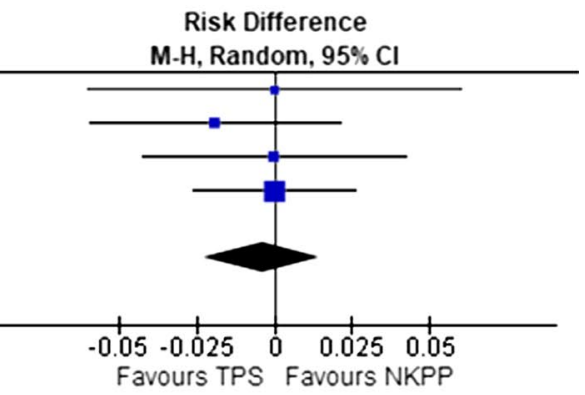

C

\begin{tabular}{lrrrrr} 
& \multicolumn{2}{c}{ TPS } & \multicolumn{4}{c}{ NKF } \\
Study or Subgroup & Events & Total & Events & Total & Weight \\
\hline Horiuchi, 2007 & 0 & 48 & 0 & 8 & $2.0 \%$ \\
Katsinelos, 2012 & 0 & 67 & 0 & 78 & $65.2 \%$ \\
Lee, 2014 & 2 & 67 & 0 & 19 & $7.0 \%$ \\
Wen, 2017 & 1 & 113 & 0 & 36 & $25.7 \%$ \\
Total (95\% Cl) & & 295 & & 141 & $100.0 \%$ \\
Total events & 3 & & 0 & &
\end{tabular}

Risk Difference

Random, $95 \% \mathrm{Cl}$

$0.00[-0.15,0.15]$

$0.00[-0.03,0.03]$

$0.03[-0.05,0.11]$

$0.01[-0.03,0.05]$

$0.00[-0.02,0.03]$

Heterogeneity. $\mathrm{Tau}^{2}=0.00 ; \mathrm{Chi}^{2}=0.63, \mathrm{df}=3(\mathrm{P}=0.89) ; \mathrm{I}^{2}=0 \%$

Test for overall effect: $Z=0.40(P=0.69)$

Fig. 5 a Forest plot of comparison of perforation rate after transpancreatic sphincterotomy (TPS) versus double-guidewire technique (DGW) in prospective studies; b comparison of perforation rate after TPS versus needle-knife precut papillotomy (NKPP) in prospective

Acknowledgments Open access funding provided by University of Pécs (PTE).

Funding Funding was provided from Economic Development and Innovation Operative Programme Grant of the National Research, Development and Innovation Office (GINOP-2.3.2-15-2016-00048), and from the UNKP-17-3-I New National Excellence Program of the Ministry of Human Capacities.

\section{Compliance with ethical standards}

Competing interests The authors declare that they have no competing interests.

Open Access This article is distributed under the terms of the Creative Commons Attribution-NonCommercial 4.0 International License (http://creativecommons.org/licenses/by-nc/4.0/), which permits any noncommercial use, distribution, and reproduction in any medium, provided you give appropriate credit to the original author(s) and the source, provide a link to the Creative Commons license, and indicate if changes were made.

studies; c comparison of perforation rate after TPS versus needleknife fistulotomy (NKF) in available comparative retrospective studies

\section{References}

1. Testoni PA, Mariani A, Aabakken L, et al. Papillary cannulation and sphincterotomy techniques at ERCP: European Society of Gastrointestinal Endoscopy (ESGE) clinical guideline. Endoscopy. 2016;48:657-683.

2. Liao WC, Angsuwatcharakon $\mathrm{P}$, Isayama $\mathrm{H}$, et al. International consensus recommendations for difficult biliary access. Gastrointest Endosc. 2017;85:295-304.

3. Gyokeres T, Duhl J, Varsanyi M, Schwab R, Burai M, Pap A. Double guide wire placement for endoscopic pancreaticobiliary procedures. Endoscopy. 2003;35:95-96.

4. Goff JS. Common bile duct pre-cut sphincterotomy: transpancreatic sphincter approach. Gastrointest Endosc. 1995;41:502-505.

5. Tse F, Yuan Y, Moayyedi P, Leontiadis GI, Barkun AN. Double-guidewire technique in difficult biliary cannulation for the prevention of post-ERCP pancreatitis: a systematic review and meta-analysis. Endoscopy. 2017;49:15-26.

6. Pécsi D, Farkas N, Hegyi P, et al. Transpancreatic sphincterotomy has a higher cannulation success rate than needleknife precut papillotomy-a meta-analysis. Endoscopy. 2017;49:874-887. 
7. Kubota K, Sato T, Kato S, et al. Needle-knife precut papillotomy with a small incision over a pancreatic stent improves the success rate and reduces the complication rate in difficult biliary cannulations. J Hepatobiliary Pancreat Sci. 2013;20:382-388.

8. Madacsy L, Kurucsai G, Fejes R, Szekely A, Szekely I. Prophylactic pancreas stenting followed by needle-knife fistulotomy in patients with sphincter of Oddi dysfunction and difficult cannulation: new method to prevent post-ERCP pancreatitis. Dig Endosc. 2009;21:8-13.

9. Horiuchi A, Nakayama Y, Kajiyama M, Tanaka N. Effect of precut sphincterotomy on biliary cannulation based on the characteristics of the major duodenal papilla. Clin Gastroenterol Hepatol. 2007;5:1113-1118.

10. Goff JS. Long-term experience with the transpancreatic sphincter pre-cut approach to biliary sphincterotomy. Gastrointest Endosc. 1999;50:642-645.

11. Kozarek R. Flail, flay, or fail: needle-knife versus transpancreatic sphincterotomy to access the difficult-to-cannulate bile duct during ERCP. Endoscopy. 2017;49:842-843.

12. Kozarek RA, Ball TJ, Patterson DJ, Brandabur JJ, Traverso LW, Raltz S. Endoscopic pancreatic duct sphincterotomy: indications, technique, and analysis of results. Gastrointest Endosc. 1994;40:592-598.

13. Moher D, Liberati A, Tetzlaff J, Altman DG. Preferred reporting items for systematic reviews and meta-analyses: the PRISMA statement. Ann Intern Med. 2009;151:264-269.

14. Wells GA SB, O'Connell D, Peterson J, Welch V, et al. The Newcastle-Ottawa Scale (NOS) for assessing the quality of nonrandomized studies in meta-analysis. 2011; Available: http://www. ohri.ca/programs/clinical_epidemiology/oxford.asp.

15. Higgins JP, Altman DG, Gøtzsche PC, et al. The cochrane collaboration's tool for assessing risk of bias in randomised trials. Bmj. 2011;343:d5928.

16. DerSimonian R, Laird N. Meta-analysis in clinical trials. Control Clin Trials. 1986;7:177-188.

17. Higgins JP, Green S. Cochrane handbook for systematic reviews of interventions, vol. 4. New York: Wiley; 2011.

18. Egger M, Davey Smith G, Schneider M, Minder C. Bias in meta-analysis detected by a simple, graphical test. $B m j$. 1997;315:629-634.

19. Cha S-W, Kim SH, Kim A, et al. 447 DGT versus TPS in patients with initial PD cannulation by chance; prospective randomized multi-center study. Gastrointest Endosc. 2012;75:AB141.

20. Sugiyama $H$, Tsuyuguchi $T$, Sakai $Y$, et al. Transpancreatic precut papillotomy versus double-guidewire technique in difficult biliary cannulation: prospective randomized study. Endoscopy. 2018;50:33-39.

21. Yoo YW, Cha SW, Lee WC, Kim SH, Kim A, Cho YD. Double guidewire technique versus transpancreatic precut sphincterotomy in difficult biliary cannulation. World J Gastroenterol. 2013;19:108-114.

22. Kim CW, Chang JH, Kim TH, Han SW. Sequential double-guidewire technique and transpancreatic precut sphincterotomy for difficult biliary cannulation. Saudi J Gastroenterol. 2015;21:18-24.

23. Zou XP, Leung JW, Li YH, et al. Comparison of sequential pancreatic duct guidewire placement technique and needle knife precut sphincterotomy for difficult biliary cannulation. J Dig Dis. 2015;16:741-746.

24. Catalano MF, Linder JD, Geenen JE. Endoscopic transpancreatic for inaccessible obstructed papillary septotomy bile ducts: comparison with standard pre-cut papillotomy. Gastrointest Endosc. 2004;60:557-561

25. Zang J, Zhang C, Gao J. Guidewire-assisted transpancreatic sphincterotomy for difficult biliary cannulation: a prospective randomized controlled trial. Surg Laparosc Endosc Percutaneous Tech. 2014;24:429-433.
26. Espinel-Diez J, Pinedo-Ramos E, Vaquero-Ayala L, AlvarezCuenllas B, Ojeda-Marrero V. Combined precut in difficult biliary cannulation. Rev Esp Enferm Dig. 2013;105:334-337.

27. Katsinelos P, Gkagkalis S, Chatzimavroudis G, et al. Comparison of three types of precut technique to achieve common bile duct cannulation: a retrospective analysis of 274 cases. Dig Dis Sci. 2012;57:3286-3292. https://doi.org/10.1007/s 1062 0-012-2271-8.

28. Lee YJ, Park YK, Lee MJ, Lee KT, Lee KH, Lee JK. Different strategies for transpancreatic septotomy and needle knife infundibulotomy due to the presence of unintended pancreatic cannulation in difficult biliary cannulation. Gut Liver. 2015;9:534-539.

29. Wen J, Li T, Gong B. Efficacy and safety of transpancreatic septotomy, needle-knife fistulotomy or both selected based on unintentional pancreatic access and papillary morphology. J Dig Dis. 2017; $18: 41$

30. Kahaleh M, Tokar J, Mullick T, Bickston SJ, Yeaton P. Prospective evaluation of pancreatic sphincterotomy as a precut technique for biliary cannulation. Clin Gastroenterol Hepatol. 2004;2:971-977.

31. Weber A, Roesch T, Pointner S, et al. Transpancreatic precut sphincterotomy for cannulation of inaccessible common bile duct: a safe and successful technique. Pancreas. 2008;36:187-191.

32. Akashi R, Kiyozumi T, Jinnouchi K, Yoshida M, Adachi Y, Sagara K. Pancreatic sphincter precutting to gain selective access to the common bile duct: a series of 172 patients. Endoscopy. 2004;36:405-410.

33. Barakat MT, Girotra M, Huang RJ, et al. Goff trans-pancreatic septotomy is an effective and safe salvage technique following failed standard biliary cannulation at ERCP. Gastrointest Endosc. 2017;85:AB606.

34. Chan CH, Brennan FN, Zimmerman MJ, Ormonde DG, Raftopoulos SC, Yusoff IF. Wire assisted transpancreatic septotomy, needle knife precut or both for difficult biliary access. J Gastroenterol Hepatol. 2012;27:1293-1297.

35. de-la-Morena-Madrigal EJ. Impact of combined precut techniques on selective biliary cannulation. Rev Esp Enferm Dig. 2013;105:338-344.

36. de-la-Morena-Madrigal EJ, Rodriguez Garcia MF, Galera Rodenas AB, Perez Arellano E. Biliary cannulation effectiveness and pancreatitis risk using two early precut techniques. Rev Esp Enferm Dig. 2018;110:74-81.

37. Esmaily S, Elzubier M, Dwarakanath D, et al. Transpancreatic sphincterotomy: a valuable technique for gaining CBD access. United Eur Gastroenterol J. 2017;5:A697.

38. Halttunen J, Keranen I, Udd M, Kylanpaa L. Pancreatic sphincterotomy versus needle knife precut in difficult biliary cannulation. Surg Endosc. 2009;23:745-749.

39. Huang C, Kung J, Liu Y, et al. Use of double wire-guided technique and transpancreatic papillary septotomy in difficult ERCP: 4-year experience. Endosc Int Open. 2016;4:E1107-E1110.

40. Javia SB, Priyanka P, Avila N, et al. Transpancreatic sphincterotomy (Goff septotomy) is safe and effective in patients with failed wire/contrast guided biliary cannulation. Gastrointest Endosc. 2016;83:AB606.

41. Kapetanos D, Kokozidis G, Christodoulou D, et al. Case series of transpancreatic septotomy as precutting technique for difficult bile duct cannulation. Endoscopy. 2007;39:802-806.

42. Liao C, Park W, Chen A, Friedland S, Banerjee S. Goff trans-pancreatic septotomy is an effective and safe biliary cannulation technique for patients who fail standard biliary cannulation. Am J Gastroenterol. 2011;106:S56-S56.

43. Lin LF. Transpancreatic precut sphincterotomy for biliary access: the relation of sphincterotomy size to immediate success rate of biliary cannulation. Diagn Ther Endosc. 2014;2014:864082. 
44. McGonigle J, Mitra V, Dwarakanath D, Chaudhury B, Majumdar $\mathrm{D}$, Hancock J. The safety and efficacy of transpancreatic sphincterotomy for difficult CBD cannulation during ERCP. Pancreatology. 2014;14:S25-S26.

45. Miao L, Li QP, Zhu MH, et al. Endoscopic transpancreatic septotomy as a precutting technique for difficult bile duct cannulation. World J Gastroenterol. 2015;21:3978-3982.

46. Miyatani H, Yoshida Y. Endoscopic needle knife precut papillotomy for inaccessible bile duct following failed pancreatic duct access. Clin Med Gastroenterol. 2009;2009:1-5.

47. Wang P, Zhang W, Liu F, et al. Success and complication rates of two precut techniques, transpancreatic sphincterotomy and needleknife sphincterotomy for bile duct cannulation. J Gastrointest Surg. 2010;14:697-704.

48. Zhong H, Wang X, Yang L, Miao L, Ji G, Fan Z. Modified transprepancreatic septotomy reduces postoperative complications after intractable biliary access. Medicine (Baltimore). 2018;97:e9522.

49. Cotton P, Lehman G, Vennes J, et al. Endoscopic sphincterotomy complications and their management: an attempt at consensus. Gastrointest Endosc. 1991;37:383-393.
50. Sterne JA, Gavaghan D, Egger M. Publication and related bias in meta-analysis: power of statistical tests and prevalence in the literature. J Clin Epidemiol. 2000;53):1119-1129.

51. Rashdan A, Fogel EL, McHenry L Jr, Sherman S, Temkit M, Lehman GA. Improved stent characteristics for prophylaxis of postERCP pancreatitis. Clin Gastroenterol Hepatol. 2004;2:322-329.

52. Lawrence C, Cotton PB, Romagnuolo J, Payne KM, Rawls E, Hawes RH. Small prophylactic pancreatic duct stents: an assessment of spontaneous passage and stent-induced ductal abnormalities. Endoscopy. 2007;39:1082-1085.

53. Gódi S, Pécsi D, Hegyi P, et al. Initial experiences with transpancreatic sphincterotomy in Hungarian centers based on prospectively collected registry data. Endoscopy. 2019;51:S76.

Publisher's Note Springer Nature remains neutral with regard to jurisdictional claims in published maps and institutional affiliations. 